Running head: FERTILITY NORMS

\title{
Low-Income Women Describe Fertility-Related Expectations: \\ Descriptive Norms, Injunctive Norms, and Behavior
}

[This is an Accepted Manuscript of an article published by Taylor \& Francis Group in Health Communication on December 9, 2010, available online:

http://dx.doi.org/10.1080/10410236.2010.521909]

\section{Author Note}

Jennifer J. Bute (Ph.D., University of Illinois at Urbana-Champaign) is an assistant professor in the School of Communication Studies at Ohio University. Robin E. Jensen (Ph.D., University of Illinois at Urbana-Champaign) is an assistant professor in the Department of Communication at Purdue University. Correspondence should be addressed to Jennifer J. Bute, School of Communications Studies, Ohio University, Lasher Hall, Athens, OH, 45701. Email: bute@ohio.edu.

A previous version of this paper was presented at the annual meeting of the International Communication Association in May 2009. The authors would like to thank the Regenstrief Center for Healthcare Engineering at Purdue University for support of this project. We are also grateful to Lynn Harter and three anonymous reviewers for their helpful feedback on earlier versions of this manuscript. 


\begin{abstract}
Social norms surrounding sexuality, pregnancy, and childbearing may help guide women's healthrelated behaviors. In this study, we explore low-income women’s perceptions of fertility-related norms by allowing women to describe their experiences with normative expectations. Semistructured interviews $(N=30)$ suggested that women in low-income subject positions articulate descriptive norms that generally correspond with mainstream descriptive norms, identify two major sources of injunctive norms concerning fertility and sexuality—authoritative and peer-oriented, and often align their behaviors according to sub-group expectations communicated in the form of peeroriented injunctive norms. We discuss these results in light of the extant literature on social norms.
\end{abstract}




\section{Low-Income Women Describe Fertility-Related Expectations:}

Descriptive Norms, Injunctive Norms, and Behavior

Fertility-related issues such as contraception, pregnancy, childbearing, and sexuality play a central role in shaping the lives of women in the United States. According to the 2002 National Survey of Family Growth, 14 percent of births to women between the ages of 15 and 44 were unwanted at the time of conception (Chandra, Martinez, Mosher, Abma, \& Jones, 2005). The same survey also revealed that 12 percent of women reported a physical difficulty getting pregnant or carrying a baby to term. These statistics draw attention to the complex issues surrounding women's control (or lack of control) over their fertility. Women cope with situations in which pregnancy is unintended or undesired as well as situations in which pregnancy is desired but difficult to achieve. As women navigate the terrains of fertility-related issues, they likely compare their behaviors to social norms about desired and ideal behaviors.

Yet, not all women experience and are judged by the same sets of fertility-related norms. Rapp (2001) discussed norms surrounding fertility and sexuality in terms of "stratified reproduction,” defined as “the hierarchical organization of reproductive health, fecundity, birth experiences, and child rearing that supports and rewards the maternity of some women, while despising or outlawing the mother-work of others” (p. 469). From this perspective, many marginalized groups, such as low-income women, may struggle to find a voice in the hierarchy of reproductive health, and they might also find that following dominant norms about fertility can be enormously problematic, especially when norms conflict, are unstable, or are unrealistic.

Our goal in this paper is to contribute to existing literature on social norms and the relationship among communication, norms, and behavior by asking members of an understudied population (e.g., low-income women) to discuss a normatively-oriented topic (e.g., fertility and 
sexuality) in their own words. More specifically, we asked low-income women what they considered to be normative practices and ideal behaviors. This project works not only to increase knowledge of how norms relate to low-income women’s behaviors, it also examines the sources of messages about social norms through the lens of existing normative theory.

In the following sections, we provide an overview of research on norms surrounding fertility and sexuality in the United States and outline a theoretical framework useful for understanding fertility-related norms. We then explain the methods we used to explore women's understandings of these norms and present the results of in-depth, semi-structured interviews with a sample of 30 low-income women. We conclude by discussing the implications of these findings in light of the extant literature exploring social norms in various health-related contexts.

Fertility-Related Norms in the United States

Dominant norms about fertility and sexuality in the United States (i.e., norms that are widely accepted among privileged European Americans) are wide ranging but seem to indicate a preferred window of time in which women should become sexually active and begin having children (Geronimus, 2003). Delayed sexuality and childbearing is highly valued among privileged groups and is a salient goal many parents have for their children (Geronimus, 2003). This norm of delayed fertility is communicated through messages of social control and is the basis for judging those both in and out of dominant groups who violate the norm (Geronimus, 2003). Yet women of privileged backgrounds, particularly those who pursue careers, are often criticized if they wait too long to have children (Harter, Kirby, Edwards, \& McClanahan, 2005). Thus, both early childbearing and delayed childbearing might be discouraged or even considered unacceptable in particular circumstances. 
Norms also exist to guide the "perfect” family size. In general, family sizes smaller or larger than the two or three child ideal are often stigmatized and subject to social sanctions, including negative stereotyping, unsolicited advice from health care providers, and intrusive questions from others (Author, in press; Mueller \& Yoder, 1997, 1999). Women and couples from privileged groups who choose to remain childfree might be in the greatest danger of social stigmatization (Durham, 2008), as remaining voluntarily childfree is "a risky choice fraught with negative evaluations” (Mueller \& Yoder, 1997, p. 218).

Dominant norms are sometimes used as a basis of judgment for those inside and outside the dominant group. However, individuals representing marginalized groups may develop their own norms for sexuality and fertility that ensure both economic and reproductive success (Geronimus, 2003). Differences in norms about fertility and sexuality among subgroups in the U.S. are related to deeply-held cultural values, structural constraints, and historical inequities (Afable-Munsuz \& Brindis, 2006; Denner, Kirby, Coyle, \& Brindis, 2001; Pagnini \& Morgan, 1996). For instance, Geronimus argued that early sexuality and childbearing is sometimes an acceptable and adaptive practice for particular groups (e.g., urban, economically-disadvantaged African American women) because it can offer a means of contending with structural constraints (e.g., inadequate health care, disadvantaged neighborhoods) that affect women's health and shorten their life expectancy. And early fertility might be encouraged as a way to enhance community vitality when family structures are multigenerational. Moreover, when women view children as an important source of social capital (i.e., meaning that having children can produce social rewards, including instrumental and emotional benefits), they are more likely to have an out-of-wedlock birth (Schoen \& Tufis, 2003). Yet, dominant norms gloss over adolescent and nonmarital childbearing as deviant practices because recognizing teenage or nonmarital sexuality 
and pregnancy as adaptive, even beneficial, practices would mean acknowledging social inequities the dominant group might prefer to ignore (Geronimus, 2003). Indeed, research suggests that adolescents from economically-disadvantaged neighborhoods are more likely to hold orientations that support early sex and childbearing (Browning \& Burrington, 2006).

Contradictory norms about sexuality and fertility can create problematic positions for women, particularly those from disadvantaged economic circumstances. Although violation of dominant norms can be adaptive and beneficial in some ways, women who violate these prevailing norms might pay a price in terms of social stigmatization and concomitant sanctions because conflicting norms “coexist in the same political and economic space” (Geronimus, 2003, p. 888). Thus, we sought to unpack how women in particular socio-economic positions articulate, learn about, and understand norms concerning fertility and sexuality-related issues.

Theoretical Framework

Communication scholars have explored norms in a variety of health-related contexts (e.g., Boer \& Westhoff, 2006; Park \& Smith, 2007; Rimal, 2008). In such studies, norms are typically defined as “codes of conduct that either prescribe or proscribe behaviors” (Rimal \& Real, 2003, p. 185). When communicated to individuals, these codes of conduct tend to serve as “convenient decision-making heuristics” potentially shaping individuals’ attitudes, behavioral intent, and/or behaviors (Lapinski \& Rimal, 2005, p. 128).

But not all norms are the same, and there have been a number of theoretical attempts to differentiate among norms, their various roles and functions, and their relationship to behavior (e.g., theory of reasoned action/ theory of planned behavior: Ajzen, 1985; 1988; Ajzen \& Fishbein, 1980; Fishbein \& Ajzen, 1975; social judgment theory: Sherif, 1936; Sherif, Sherif, \& Nebergall, 1965; Smith et al., 2006). In 1990, Cialdini, Reno, and Kallgren distinguished 
between descriptive and injunctive norms, a differentiation that became central to the theory of normative social behavior (TNSB). The TNSB posits that descriptive norms (i.e., norms describing the perceived prevalence of a behavior in the general population) are related to behavior/behavioral intent, and that the associations between descriptive norms and behavior should take into account important moderating influences such as injunctive norms, outcome expectancies, group identity, and ego involvement/behavioral identity. Injunctive norms refer to what individuals believe those close to them think they "ought” to do. The TNSB maintains that when descriptive and injunctive norms are congruent they may be more likely to affect behavior; when these norms are antagonistic the effect is likely to be muted (Rimal, 2008).

Injunctive norms are connected to a second moderator in the TNSB, an outcome expectation, which refers to people's sense that if they behave in an expected way, they will experience benefits. Conversely, outcome expectations also involve people's sense that if they do not behave in an expected way, they will experience social sanctions and miss out on socialization opportunities (Rimal, Lapinski, Cook, \& Real, 2005). Beyond injunctive norms and outcome expectations, the TNSB also identifies group identity (i.e., whether a person identifies highly with the group in question) and ego involvement or behavioral identity (i.e., whether a behavior is part of a person’s self identification; Lapinski \& Rimal, 2005) as moderating variables in the relationship between descriptive norms and behaviors.

Despite a number of excellent empirical studies on the relationship between norms and behavior, Rimal et al. (2005) explained that norms remain an ambiguous theoretical concept. This is especially true because several elements of predictive models such as the TNSB remain unclear, including the communicative sources of injunctive norms and how conflicts between descriptive and injunctive norms are resolved. In addition, little research has explored norms, 
their communication, and their relationship to behavior in the context of traditionally underserved health populations such as low-income women. Given that norms are "contextdependent prototypes” (Hogg \& Reid, 2006, p. 7), explicating the TNSB depends on attempts to look closely at what members of specific groups and sub-groups perceive as normative, how they learn about norms, and how they perceive norms as connected with behavior. This is especially true when the issues at hand are particularly normatively-oriented, such as in the case of fertility and sexuality-related decisions and behaviors. Thus, the present study explores how low-income women describe, learn about, and connect norms with behaviors regarding fertility and sexualityrelated issues based on the following research questions:

RQ1: How do low-income women describe social norms for the general population of women regarding fertility and sexuality?

RQ2: How do low-income women describe the sources of information about injunctive norms regarding fertility and sexuality?

RQ3: How do low-income women connect messages about descriptive and injunctive norms with their own and others' behaviors?

In the following section we describe the methods we used to answer these questions.

Methods

\section{Recruitment}

After the study received Institutional Review Board approval, we recruited participants in conjunction with a separate study on health literacy in low-income populations. The health literacy study targeted participants from three low-income communities who had income levels at $200 \%$ of the poverty line or below, as evidenced by their qualification for and participation in state-wide university extension programs. Staff members from these programs, who were 
members of the target populations (i.e., they received services from the extension programs), asked women in their programs if they were interested in participating in research being conducted by a public university in their state. If a woman indicated interest in the fertility study, the research team member gave her a consent form that explained the study in detail and asked her to complete a participant contact sheet. We used that information to contact women who expressed interest in the fertility study and schedule telephone interviews.

\section{Data Collection}

We used qualitative telephone interviews to explore women's attitudes and beliefs about fertility-related norms. Interviews are an appropriate and useful method for exploring the lives of women whose voices have been neglected or even ignored because "interviewing offers researchers access to people’s ideas, thoughts, and memories in their own words rather than in the words of the researcher” (Reinharz, 1992, p. 19). Moreover, a qualitative approach is particularly fitting given the complex and personal nature of the research questions explored in this study. Scholars have also noted that interviews are an especially suitable mode of data collection when targeting individuals who may lack the confidence or ability to write down answers or complete surveys (Collins, 1990; Madriz, 2001; Muturi, 2005). We chose to use telephone interviews, rather than face-to-face interviews, for several reasons. First, we wanted to respect the difficult life circumstances of many of the women we interviewed. Some of them lived in transitional housing or were staying with relatives temporarily. Others had trouble accessing transportation for themselves or child care for their young children. Despite these obstacles, all women in our study had access to a telephone. In fact, many had their own cellular phones, even if they did not have permanent housing. Thus, we called women and conducted interviews at their convenience to ease the burden of coordinating transportation, child care, and 
private interview locations. Moreover, because many of our interview questions dealt with private or sensitive issues, such as sexual intercourse, telephone interviews provided a facesaving medium for women to reveal highly personal experiences (Reymert \& Hunskarr, 1994).

All interviews were conducted by one of the study's authors. At the beginning of each interview, the researcher took careful steps to explain the informed consent process thoroughly and to allow women to ask questions about the study. We were keenly aware that the women in our sample might be unfamiliar with the informed consent process and were committed to allowing ample time for decision-making and questions prior to commencing the interview. After participants consented to the study, the interviewer asked a series of brief questions to collect demographic information (e.g., age, marital status, education). The semi-structured interview guide included a series of questions designed to explore women's experiences with fertility-related issues, including sexual intercourse, pregnancy/childbirth, and contraceptive use. Specific topics addressed during the interviews included: (a) access to information about fertility-related issues, (b) talking to friends or family members about fertility-related issues, (c) talking to health care providers about fertility-related issues, (d) formal and informal sexual education experiences, and (e) societal and individual expectations about sexuality and pregnancy. Each woman who participated in the study received a \$30 retail gift certificate. Interviews lasted between 20 and 90 minutes and were tape recorded and transcribed verbatim. The authors then double-checked each transcript against the original interview recordings.

\section{Participants}

We interviewed a total of 30 women who agreed to take part in the study. Participants ranged in age from 18 to 48 years, with an average age of 29 years. Six women were married at the time of the interview, nine were divorced, and fifteen were single. Three of the single women 
were engaged to be married at the time of the interview. All but two women in the sample had at least one child as a result of a pregnancy or a marriage (i.e., a stepson or stepdaughter). Of the two women who did not have children, one was pregnant at the time of her interview.

The women in our sample represented a variety of racial/ethnic backgrounds. Seventeen women identified themselves as white or Caucasian, eight identified as black or AfricanAmerican, and two identified as Hispanic. Three women reported a mixed heritage (e.g., half Jamaican and half Norwegian). Women also reported their highest level of education. Three had completed either an associate's or bachelor's degree. Twelve had completed some college; nine had completed high school, and six women had less than a high school education. Fifteen of the women were employed outside the home in a variety of occupations including supervisor, cashier, social worker, and staffing assistant. Seven women described themselves as housewives or stay-at-home moms, and three women were students. Five women described themselves as disabled or unemployed at the time of the interview. Finally, fifteen of the women were on Medicaid, and six women had no access to health insurance. Eight women had employer-based health insurance, and one woman reported that she was unsure about her health insurance status.

\section{Data Analysis}

Because qualitative data analysis is an ongoing, iterative process, we conducted several rounds of intensive analysis (Strauss \& Corbin, 1990). We recorded and exchanged field notes after every interview and regularly discussed theoretical possibilities and methodological adjustments (e.g., rewording particular interview questions). As we double-checked the interview transcripts for accuracy, we gained a holistic sense of the data, and we independently recorded notes about recurrent themes. We then met to discuss those themes and decided to focus our analysis on women's discussion of fertility and sexuality-related norms. Based on our theoretical 
sensibilities, we developed a set of research questions that guided us as we both reread all 30 transcripts. Although our interview protocol included two specific questions related to normative expectations, we discovered that women discussed their experiences with social norms (e.g., the ideal age for pregnancy) at various points in their interviews. Thus, we analyzed each interview transcript in its entirety rather than exclusively focusing on responses to specific questions. We wrote research memos during this process that we used as a basis for open and axial coding (Strauss \& Corbin, 1990), which involved categorizing and theorizing the relationships among those categories. Throughout the process of data analysis, we created an audit trail (Lincoln \& Guba, 1985) consisting of field notes, interview transcripts, and research memos. In the following section we offer a set of plausible knowledge claims about women's perceptions of and experiences with fertility-related norms. We use pseudonyms to protect participants’ anonymity.

Results

\section{Descriptive Norms}

The first research question aimed to get a sense of how low-income women described descriptive norms (i.e., what most people do and/or what members of the general population think most people do) concerning fertility and sexuality-related issues. The results for this question are reported in order of participants' general sense of what tends to come first, second, third, and so on in a woman's lifecycle. With just a few exceptions, interviewees' beliefs about descriptive norms seemed to mirror dominant descriptive norms as they have been outlined in existing research.

Many participants felt that “most people” started having sex at around 16 years of age because, as Shelby put it: 
At my time I thought it was about 16, 17 [to have first sex] before my mom even said anything, because they always told you that consent of age is 16 . So I figured I had to wait until at least I was 16 before that, so . . . because if they try to get rape on you, they can’t because it’s consensual when you're 16.”

Shelby's mention of potential legal ramifications of illicit sexual behavior may be related to her social location within a low-income community where, if serving time in jail is not more common than it is among those in many other communities, it may at least be more openly discussed. Several individuals mentioned that they, or people they knew, started having sex as early as 12 years of age, but they also noted that 12 was younger than most people "expected” a person to have sex. On the opposite end of the spectrum, several women noted that most individuals were sexually active by the time they were in their early 20s, and people who waited longer tended to be labeled "freaks."

Participants felt the general population considered pregnancy acceptable only if women met a number of specific criteria. The most explicit of these criteria involved age. Women should be neither too young nor too old when they become pregnant. Kaylene felt that women should have babies between ages 25 and 35. She demonstrated her clear grasp of what was being asked of her in the following exchange:

Interviewer: What is the timeline that most people expect for a woman in terms of when she might first have sex, when she might get pregnant, when she might stop having babies, that sort of thing?

Kaylene: For her to maybe start having sex, I would say maybe 20s. Maybe society’s seeing it that way. Now this just isn't me personally; I'm saying society. Having babies, maybe around 30—25, 30. To maybe stop having children, maybe 35. 
Aisha also spoke about the narrow window of time women had for getting pregnant without being viewed as abnormal:

Aisha: I believe just having sex, having sex altogether, I would say my ideal age would be maybe 18 to be starting. But most people know that's not when it starts. But to get pregnant, nowadays people get pregnant at some, every age. But okay, I'll speak of now. I've seen people get pregnant, mainly, from 16 and up. And I guess the ideal age people would think that they would get pregnant would be maybe 20, 22 or older.

Interviewer: And what's maybe too old to be pregnant for the first time?

Aisha: I personally think 30 - [laughs] - and a little bit older. Because I've heard that it's not always good to have kids at a real older age. And I know 30 is not old, but I've just been told that before that a lot of...you shouldn't have kids at a real late age.

The ideal ages that Aisha mentioned for initially becoming pregnant, 20 or 22, may indicate less concern for traditionally middle-to-upper-class descriptive norms such as attending institutions of higher education and establishing one's self professionally. Alex, however, communicated an even smaller window of opportunity for acceptable pregnancy, noting that most people think others should not have kids until they are 25 but then also noting that people believe women should stop having babies after their twenties because of the medical risks associated with advanced maternal age.

A second criterion that woman described as prevalent in the general population involved being married first, and, ideally, having been married for the right amount of time before becoming pregnant. Rose explained, “Most people think they should have babies, I would say, a year or two after marriage.” Other participants did not mention being married as general criterion 
for pregnancy, but they laid out other expected criteria such as financial or relational stability when becoming pregnant. For example, Lacy said:

Lacy: I guess it just depends on your finances, maybe.

Interviewer: Okay. Anything else that you think affects that decision, besides finances?

Lacy: Relationships.

Interviewer: What do you mean by relationships?

Lacy: Maybe if you've been in a stable relationship for a while, that would be better. While it could be argued that establishing healthy finances is often a criterion for all individuals considering pregnancy, it may be the case that such considerations are especially relevant for low-income individuals. And the same potentially could be said for establishing a stable relationship before pregnancy as financial concerns tend to be heightened for single parents. Participants also described norms about how big families typically grow and how much time should elapse between pregnancies. Participants discussed societal concerns about women who have more than three or four children, and some, including Tori and Sharon, argued that societal norms encouraged women to space children out by at least a couple of years. Both Rhonda and Sally claimed that most people do not expect women to become pregnant if they have older children who are in their teens or twenties because they assume those women have already raised their families and should wait for the arrival of grandchildren (rather than have more children of their own).

Many participants explained that norms changed over time, creating the impression that descriptive norms were moving targets and difficult to decipher in specific cases. Sharon explained, “I think that norm is changing. I don't think it's that they expect you to wait [to have 
sex] until you get married, but they're just more aware of being cautious, as far as safe sex.” Comments about changing norms often took on a narrative of societal decline. Marge said: In this day and age they're having sex as young as twelve years old. Pretty bad. I mean, you see it on TV, you hear it. I've heard kids talking about it. I think by twelve years old, they should bring back the basics of sex education in school.

These narratives of decline offered some participants opportunities to evaluate their own experiences with those of others and find that they did "pretty good" in comparison.

\section{Injunctive Norms}

The second research question aimed to get a sense of how women described the sources of injunctive norms (i.e., the expectations a person believes those close to her had regarding what she "ought” to do) concerning fertility and sexuality-related issues. Participants described two major categories of injunctive norm sources, authoritative and peer-oriented. In a number of cases, injunctive norms communicated from these sources aligned with dominant descriptive norms. Injunctive norms communicated from peer-oriented sources, however, generally did not align with dominant descriptive norms and may demonstrate sub-group defiance of those norms.

First, participants discussed injunctive norms communicated by authority figures such as parents and teachers. Participants mentioned that their parents in particular communicated a number of injunctive norms to them related to fertility and sexuality. For example, some parents expected their daughters to wait to have sex until they were married. Darla explained:

Yeah, I mean, my parents had pictured me to grow up and go to college and then get married and then possibly have kids. They definitely didn’t think that I would ever have sex until I was married and birth control, wait until you're married. I mean, they were very old-fashioned in their way of thinking. 
In other situations, parents joined forces with other authority figures such as doctors to send a "wait until marriage to have sex" message. Bettina, for example, demonstrated the omnipresent authoritative expectation to wait to have sex until marriage, noting that her doctor "talked to me about not having sex, like everyone does ... pretty much everybody [parents, teachers] talked about the same thing, really.” A few participants described parent-doctor expectations that they finish various levels of schooling (e.g., high school, college) before having sex or becoming pregnant.

Doctors were repeatedly cited as singular, authoritative sources for injunctive norms about when women should exit the "baby track.” Judy described getting explicit messages from her doctor encouraging her to have a tubal ligation after the birth of her third child:

Judy: Well, one in particular, by the time I had my youngest one, he kept encouraging sterilization and all this other stuff. And it's like, "I'm not married to you. You don't have the right to decide what I need, or what I don't need and stuff." So they were kinda pushin' the sterility, or the....

Interviewer: The hysterectomy, or something like that?

Judy: The newborn stuff like that, and it's like, they kept pushin' it. So that was not cool. Interviewer: That is interesting. He felt like because you had three kids that that was enough?

Judy: Yeah, that was enough, in his opinion. And he didn't have the right to push it. Interviewer: No. Do you have any sense why he would talk about sterility, or being sterile rather than birth control methods or something like that?

Judy: It was just, I don't know. It was just, [the doctor] was tellin' everybody that, they need to go and have their tubes tied and everything like this, 'cause there was too many 
kids born to people who don't want 'em. And here I've always fought for my kids and stuff. And it was like, you can't go and assume that I'm one or the other and stuff, so he just preaches on everybody, everybody that was his patient and stuff, he was preaching the tubal and everything else like that.

Judy's narrative is troubling in light of her status as a member of a low-income population. Judy's perception that the physician was urging her and other women in her low-income community to get tubal ligations could be interpreted as evidence that he was motivated, at least in part, by class discrimination.

While the majority of injunctive norms coming from authority figures seemed to follow dominant norm expectations, several interviewees claimed that authoritative sources - their parents in particular-communicated the expectation to them that they would not follow dominant descriptive norms (or would fall short of such norms). For instance, when Jaime was asked if people in her life had expectations for her regarding her timeline for sex and pregnancy, she responded:

Jaime: No. My family expected me to be the first one to be pregnant and have a kid because I was considered the black sheep of the family.

Interviewer: How so?

Jaime: I was the bad girl.

Interviewer: Okay.

Jaime: [Laughs.] I was always shoplifting and lying and stealing, so they just expected me to be the one to be the first one pregnant and everything. Still others mentioned they encountered expectations from parents that they would not follow the norm because of a family history of not following the descriptive norm. Rebecca felt that her 
mother would not have been surprised if she had gotten pregnant as a teenager because "most of the women in my family on my mom's side all had babies before they were 18, including my sister.” Rebecca’s response in particular seems to indicate a certain amount of sub-group (i.e., low-income families) defiance or rejection of dominant group norms. In this sense, the TNSB's positioning of group identity as a potential moderating factor in the relationship between the norms and behaviors is justified by the interviews in the present study; however the positioning of descriptive norms alone, rather than in combination with injunctive norms, as central to this process may be put in question.

Second, beyond injunctive norms set by authorities, participants discussed injunctive norms communicated by peers. In several key topic areas, authoritative and peer injunctive norms diverged in dramatic ways. While authorities often expected participants to wait to have sex until they were out of school, financially stable, or married, participants felt their peers generally expected them to be sexually active while they were in secondary school. Participants described situations when their friends in middle school and high school talked with them about the “dos and don'ts” of sex, as well as how “good” sexual activity felt. Leigh believed that her friends modeled the behaviors they expected of her:

Most of my friends were [on birth control]. I only had one friend that wasn't sexually active by the time I dropped out of college, or dropped out of high school, I mean. I only had one friend that wasn’t, and she became sexually active about a month before I did. Similarly, Lena described her high school friends as "wild” and felt they expected of her that same degree of sexual promiscuity.

In several cases, participants described peers who expected them to have children before marriage, an expectation at odds with injunctive norms from many authority figures and with 
dominant societal norms in the United States (Geronimus, 2003). Leigh communicated this clash in injunctive norms from her peers and injunctive norms from her grandparents:

Leigh: Well, actually, I think that the people who aren’t accepted as much are people like me who got married before they had kids. Every one of my friends is single and has one to three kids.

Interviewer: Oh, okay. That's really interesting.

Leigh: You got married and had kids, and that was always instilled in me by my grandparents, but when I went out in the world, nobody could understand that I didn't want to have kids before I got married.

Interviewer: That is really interesting. So how did you explain that to them?

Leigh: I told them that I knew it was a full-time job to take care of kids and I did not want to do it until I had somebody there to help and support me. And I couldn’t make sure that a guy was going to stick around to help and support the baby unless I had that paper saying that they had to. Because they don’t have to sign that birth certificate, and usually there's a lot of chance.

Interviewer: Right. That's true. So what was their argument for having a baby before they got married?

Leigh: Most of them it was just, well, we wanted to so we did, or it was an accident.... When I got married when I was 21, every one of my friends had at least one child. I didn’t know anybody, guys or girls, who didn’t have at least one child.

Leigh's friends were especially confused by her decision to wait to have children until marriage because she loved caring for other people’s kids and described herself as very maternal. Similarly, Brandie noted that "mostly everybody had two or three kids by the time we was 
finished with [high] school,” an observation she used to imply that her peers expected her to have children in high school, too. And Vanessa noted that many high school girls in her community romanticized the idea of having their own babies and provided their friends with tips for getting pregnant. Leigh, Brandie, and Vanessa's experiences may indicate another instance of a sub-group (i.e., low-income women) defying dominant norms (i.e., waiting to have children until high school has been completed). In these cases, defiance may be driven by a desire among sub-group members to adapt to their socio-cultural positioning and become mothers while they are healthy and can enjoy the social capital children bring multigenerational familial structures.

The majority of participants could identify injunctive norms and differentiate among normative sources, but in a few cases participants were not able to identify the sources of injunctive norms because they were unable to articulate injunctive norms at all (although they could articulate more general descriptive norms). When asked if her parents had expectations for her regarding fertility-related issues, Tammy responded:

Tammy: I really don't think so. My mom worked three jobs at the time and my dad was never home, so we were pretty much on our own. But I was just in school, and I mean, I was babysitting and all that kind of stuff. My expectation growing up was to have dinner on the table, cook dinner and stuff like that, you know? I really don't think I had too many expectations about that.

Interviewer: Okay. And do you think your parents or other people in your life had expectations for the timeline that you should follow?

Tammy: No. We really didn't talk about it a lot, especially for my dad. But my mom just tells ya, you should take birth control or whatever. 'Cause she had eleven kids. She didn't want to raise one of ours, you know? And one of my sisters is handicapped, so she's got 
her hands full with her and everything. But I never really had expectations on following a timeline or whatever I guess.

Other participants also mentioned that no one ever talked with them about their expectations and so they did not know if those expectations existed. This apparent lack of awareness concerning injunctive norms may be related to the dearth of time and energy that individuals in low-income subject positions have for forming, communicating, and learning about nuanced, injunctive expectations. While descriptive norms may sometimes seem more clearly defined as they pervade entire communities, injunctive norms are tied to fewer individuals and thus are less evident in some cases.

\section{Comparing Norms and Behavior}

The final research question aimed to get a sense of how women connected descriptive and injunctive norms with their own and others' behaviors. Although women were largely able to distinguish between what scholars have labeled as descriptive and injunctive norms and identify the sources of messages about injunctive norms (e.g., messages from parents, physicians, peers), their discussion of behaviors indicated that the relationship between messages prescribing fertility-related norms and individuals’ behavior is somewhat tenuous. Women themselves and people they knew frequently violated normative expectations, particularly dominant norms and authoritative injunctive norms.

Many participants mentioned a gap between societal level, descriptive norms and others’ behaviors. Jessica drew attention to this gap by asking the interviewer to clarify the question: “When should they [have sex] or when do they [have sex]?” Anita explained that although people are generally expected to wait until marriage to have sex, 
In reality for when I was a teenager, I guess a lotta my friends maybe around 15 or 16 lost their virginity. By 17 or 18, they were probably pregnant. A few of them had abortions while we were in high school. I had one friend who did have a kid when she was 12 and gave it up for adoption—open adoption. I mean, these were things we knew about, but that's kinda like what it was.

Rebecca also discussed this “reality,” explaining, “I think, technically, everybody expects you to wait until you're 18, but everybody knows most 18-year-olds are not virgins.”

In many cases, participants also recognized a gap between descriptive norms and their own behaviors. Sometimes participants discussed this difference with regret, as was the case for Vanessa, a 24-year-old single mother:

I wish I could have waited so I could have brought my son into a better world than, you know, like if I would have had my own house already, if I had a real good job so we wouldn’t have to struggle sometimes. I wish I would have waited until I was finished with school and stuff.

Before delineating descriptive norms, Rita qualified her response by saying, "and it’s not the way I’ve done it, but now this is the way I see it.” Like Vanessa, Rita regretted defying what she saw as descriptive norms about waiting to have children until marriage or achieving financial and relational stability.

Correspondingly, the majority of participants noted that they behaved in ways not sanctioned by authoritative injunctive norms (which makes sense as we found that descriptive norms and authoritative injunctive norms were likely to overlap). As a result, some found themselves in dangerous situations. Sharon said: 
Growing up, I believed everything my grandma believes, and that you shouldn't have sex before marriage, and blah-blah-blah. I came from a Christian background. You go away to college, and you live on your own, and you kind of learn to think for yourself, I guess. At least I did. There were times where I had unsafe sex, and I'd worry about it after the fact, and I'd really stress over it. Which, I should have, I was given the information, but I guess you think, "It's not going to happen to me." I wish I would've taken the information more to heart. I've been very lucky that ... I have had unsafe sex, and been with people without condoms.

The worry that Sharon described after violating her grandmother's injunctive norms was discussed by many participants, often in combination with feelings of shame and self-loathing. Melanie noted that she "cried a lot" when she got pregnant at 17 because "it was disappointing to myself, being so young and never wanting to be that way until I was married.” Jessica explained: And I think they had the Love Waits thing. And you signed a paper saying that you weren't going to have sex and it was sent to Washington. And I was really proud of signing that. So when I started getting sexually active at 17, I was disappointed in myself. But I felt like, okay, I've done it now. Then why stop? And I realize now, okay, that was a dumb thing to think.

Jessica's shame and disappointment at failing to meet authoritative injunctive norms, largely promoted by her church in this case, led to her attitude that it was already "too late" and she might as well continue engaging in sexual activity.

The defiance of dominant or authoritative injunctive norms, however, sometimes meant women were actually complying with a contrasting set of expectations, peer injunctive norms. Vanessa, for example, described messages from her peers that encouraged early childbearing by 
romanticizing motherhood and pregnancy. When Vanessa became a single mother at the age of 21, she violated dominant and authoritative norms that prohibit nonmarital sex and childbearing yet actually complied with sub-group norms among her peers. Similarly, Jessica expressed regret for violating a virginity pledge that advised abstinence until marriage but attributed her early sexual activity to the "crowd" she associated with when she became sexually active. The experiences of Vanessa, Jessica, and others like them illustrate the highly complex relationship between norms and behavior and draw our attention to the fact that the same behavior (e.g., early pregnancy, nonmarital sex) can both comply with one set of norms while simultaneously violating another set of norms.

Finally, although many participants’ behavior defied descriptive or authoritative injunctive norms, it should be noted that some participants' behavior aligned with these norms. Although Aisha had sex before marriage, she stopped doing so when she "gave her life to God.” This authoritative injunctive norm was “the main reason” she decided to stop having sex. Similarly, Judy followed the edict of her church and did not have sex while in high school. And Darla was so scared of ruining the reputation of her father, who held a public office, that she did not become sexually active until she got married when she was 18 .

\section{Discussion and Implications}

This study allowed low-income women to express in their own words their understanding of normative expectations surrounding sexuality and fertility, thus contributing to our theoretical understanding of social norms for individuals representing under-explored subject positions. Women expressed detailed descriptive norms about the onset of sexual activity, the ideal timing of pregnancy, and the specific life circumstances conducive to raising children. They also identified the major sources of messages about injunctive norms, which we categorized into 
authority figures and peers. These distinctive sets of injunctive norms can come from a variety of sources and can sometimes promote divergent behavioral expectations. Finally, women compared their understanding of descriptive and injunctive norms to their own and others' behaviors. Although some women in the sample had followed others’ expectations for sexuality and childbearing, the majority of the women in our sample described either violating descriptive and authoritative injunctive norms or noted that others in their immediate social network had done so. Violations of norms, even violations that result in a joyous addition to a family, can result in guilt, shame, and disappointment for women. Such consequences might be amplified for women in marginalized groups, such as women living in poverty, when prevailing descriptive norms dictate a preference for delayed sexuality and childbearing and when public opinion condemns low-income women for having too many children.

The results of our study can be interpreted in light of several theoretical implications. First, scholars have indicated a need to distinguish among various types of social norms in order to tease out the relationship between normative expectations and behaviors (Lapinski \& Rimal, 2005; Rimal \& Real, 2003). Our findings support the need for such distinctions. Many women in our sample noted a clear difference between what people ought to do (injunctive norms) and what people actually do (descriptive norms). Recall, for instance, Jessica, who asked the interviewer to clarify a question about norms by asking if the interviewer wanted to know when people should begin having sex or when people do begin having sex. Notably, a few women in our sample were not able to articulate injunctive norms for themselves, yet they were able to describe more general expectations about fertility-related norms. One woman even expressed regret that no one in her life had engaged her in a serious and focused conversation about when 
to have sex. She speculated that she might have waited until after high school or even after marriage to have sex if someone had had a conversation with her about such expectations. Beyond our discovery that participants distinguished between descriptive and injunctive norms, evidence from women's interviews suggests that behaviors might be guided by at least two sets of injunctive norms, authoritative injunctive norms and peer injunctive norms. Women described authoritative injunctive norms that in most cases paralleled dominant descriptive norms and peer injunctive norms that were often incongruent with authoritative and descriptive norms. Thus, in some cases, norms about what women ought to do varied according to the source of the message about those norms. Norms from peers that encouraged early sexual activity and pregnancy (e.g., some women in our sample were ostracized for not getting pregnant in high school) conflicted with norms from authority figures, like parents, who discouraged sex and pregnancy before marriage. Injunctive norms about what women ought to do can conflict, just as descriptive norms and injunctive norms can be incongruent (Rimal, 2008).

When it comes to guiding behaviors, messages about peer expectations sometimes seemed to have more import for participants than did authoritative expectations, a finding that may extend Hogg and Reid's (2006) claim that some group members, particularly leaders, may be more influential than others. Our findings indicate that sometimes those individuals with little explicit authoritative power may have the most influence over the normative perceptions of those in their group. It is also possible that peer injunctive norms are highly influential because individuals perceive their peers as more similar to themselves in contrast to authority figures, whom they may perceive as less similar. Thus, scholars of health communication and social norms should continue examining the dispersion of messages about injunctive norms, including how such messages can vary according to the source and how divergent messages could 
potentially have differential impacts on health related behaviors. We also noted that in some cases it is possible for a particular behavior to simultaneously breach one set of norms while following a contradictory set of norms. These findings suggest that the theory of normative social behavior may need to reposition injunctive norms in a more central position, rather than a moderating position, in the relationship between norms and behavior. The influence of contradictory injunctive norms on behaviors still remains somewhat unclear, but it would behoove social norms scholars to continue exploring the existence of multiple sets of injunctive norms to determine how individuals resolve these confusing messages and how these norms serve as a guide for health-related behaviors.

While most women in our sample were aware of dominant descriptive norms that suggest ideal behaviors, many seemed to be influenced by the sort of sub-group norms suggested by Gernonimus (2003). Findings from our study support previous research suggesting that marginalized groups develop and communicate their own social norms regarding sexuality and fertility that might contradict those of dominant groups (Geronimus, 2003). For instance, peer injunctive norms encouraging teenage pregnancy described by some women in our study are likely unique to this sub-group and are unlikely to operate in the same way among women from more privileged socioeconomic classes. However, these sub-group norms can serve vital functions in particular communities, such as low-income communities, by promoting multigenerational families in which grandparents aid in the care of young children and/or young women benefit from the positive social capital that children can provide (Schoen \& Tufis, 2003). Overall, our findings suggest that individuals’ social locations shape their accounts of and experiences with social norms. Our results imply the means through which women learn (or do not learn) about fertility-related norms (e.g., through interactions with health care providers or 
conversations with friends). Future research should continue to investigate the relationship between norms, messages about norms, and behavior, especially in the context of individuals representing traditionally marginalized groups who might lack access to health care and healthrelated information. Exploring how various sub-groups learn about social norms could inform future health campaigns and interventions.

Finally, although including the voices of low-income women is an important contribution of this investigation, their voices are only one part of the equation. In that respect, future research could extend our work by bringing in the voices of men to better realize how they experience and make sense of fertility-related norms. Male perceptions of and communication about fertility and sexuality-related norms may not correspond with existing findings related to women. Such studies could explore whether and how men's understandings of normative expectations differ from women's while recognizing the relational nature of many decisions related to fertility and sexuality. Overall, the perspectives of the women in this study are highly valuable, especially given their particular life circumstances. Their sense of expectations related to fertility, especially when articulated in their own words, enhances current understandings of social norms theory, as well as fertility- and sexuality-related communication. 


\section{References}

Afable-Munsuz, A., \& Brindis, C. D. (2006). Acculturation and the sexual and reproductive health of Latino youth in the United States: A literature review. Perspectives on Sexual and Reproductive Health, 38, 208-219.

Ajzen, I. (1985). From intentions to actions: A theory of planned behavior. In J. Kuhl \& J. Beckman (Eds.), Action-control: From cognitions to behavior (pp. 11-39). Heidelberg, Germany: Springer.

Ajzen, I. (1988). Attitudes, personality and behavior. Milton-Keynes, UK: Open University Press.

Ajzen, I., \& Fishbein, M. (1980). Understanding attitudes and predicting social behavior. Englewood-Cliffs, NJ: Prentice-Hall.

Author. (in press). "Nobody thinks twice about asking:" Women with a fertility problem and requests for information. Health Communication.

Boer, H., \& Westhoff, Y. (2006). The role of positive and negative signaling communication by strong and weak ties in the shaping of safe sex subjective norms of adolescents in South Africa. Communication Theory, 16, 75-90.

Browning, C. R., \& Burrington, L. A. (2006). Racial differences in sexual and fertility attitudes in an urban setting. Journal of Marriage and Family, 68, 236-251.

Chandra, A., Martinez, G., Mosher, W., Abma, J., \& Jones, J. (2005). Fertility, family planning, and reproductive health of U.S. women: Data from the 2002 National Survey of Family Growth.: National Center for Health Statistics. 
Cialdini, R. B., Reno, R. R., \& Kallgren, C. A. (1990). A focus theory of normative conduct: Recycling the concept of norms to reduce littering in public places. Journal of Personality and Social Psychology, 58, 1015-1026.

Collins, P. H. (1990). Black feminist thought: Knowledge, consciousness, and the politics of empowerment. New York: Routledge, Chapman \& Hall.

Denner, J., Kirby, D., Coyle, K., \& Brindis, C. (2001). The protective role of social capital and cultural norms in Latino communities: A study of adolescent births. Hispanic Journal of Behavioral Sciences, 23, 3-21.

Durham, W. T. (2008). The rules-based process of revealing/concealing the family planning decision of voluntarily child-free couples: A communication privacy management perspective. Communication Studies, 59, 132-147.

Fishbein, M., \& Ajzen, I. (1975). Belief, attitude, intention and behavior: An introduction to theory and research. Reading, MA: Addison-Wesley.

Geronimus, A. (2003). Damned if you do: Culture, identity, privilege, and teenage childbearing in the United States. Social Science \& Medicine, 57, 881-893.

Harter, L. M., Kirby, E. L., Edwards, A., \& McClanahan, A. (2005). Time, technology, and meritocracy: The disciplining of women's bodies in narrative constructions of age-related infertility. In L. M. Harter, P. M. Japp \& C. S. Beck (Eds.), Narratives, health, and healing (pp. 83-105). Mahwah, NJ: Erlbaum.

Hogg, M. A., \& Reid, S. A. (2006). Social identity, self-categorization, and the communication of group norms. Communication Theory, 16, 7-30.

Lapinski, M. K., \& Rimal, R. N. (2005). An explication of social norms. Communication Theory, $15,127-147$. 
Lincoln, Y., \& Guba, E. (1985). Naturalistic inquiry. Beverly Hills, Ca: Sage.

Madriz, E. (2001). Focus groups in feminist research. In N.K. Denzin (Ed.), Handbook of qualitative research ( $2^{\text {nd }}$ ed.), pp. 835-850. Thousand Oaks, CA: Sage.

Mueller, K. A., \& Yoder, J. D. (1997). Gendered norms for family size, employment, and occupation: Are there personal costs for violating them? Sex Roles, 36, 207-220.

Mueller, K. A., \& Yoder, J. D. (1999). Stigmatization of non-normative family size status. Sex Roles, 41, 901-919.

Muturi, N. W. (2005). Communication for HIV/AIDS prevention in Kenya: Social-cultural considerations. Journal of Health Communication, 10, 77-98.

Park, H. S., \& Smith, S. W. (2007). Distinctiveness and influence of subjective norms, personal descriptive and injunctive norms, and societal descriptive and injunctive norms on behavioral intent: A case of two behaviors critical to organ donation. Human Communication Research, 33, 194-218.

Pagnini, D. L., \& Morgan, S. P. (1996). Racial dfferences in marriage and childbearing: Oral history evidence from the south in the early twentieth century. American Journal of Sociology, 101, 1694.

Rapp, R. (2001). Gender, body, biomedicine: How some feminist concerns dragged reproduction to the center of social theory. Medical Anthropology Quarterly, 15, 466-477.

Reymert, J., \& Hunskaar, S. (1994). Why do only a minority of perimenopausal women with urinary incontinence consult a doctor? Scandinavian Journal of Primary Health Care, 12, 180-183. 
Rimal, R. N. (2008). Modeling the relationship between descriptive norms and behaviors: A test and extension of the theory of normative social behavior (TNSB). Health Communication, 23, 103-116.

Rimal, R. N., Lapinski, M. K., Cook, R. J., \& Real, K. (2005). Moving toward a theory of normative influences: How perceived benefits and similarity moderate the impact of descriptive norms on behaviors. Journal of Health Communication, 10, 433-450.

Rimal, R. N., \& Real, K. (2003). Understanding the influence of perceived norms on behaviors. Communication Theory, 13, 184-203.

Reinharz, S. (1992). Feminist methods in social research. New York: Oxford University Press.

Schoen, R., \& Tufis, P. (2003). Precursors of nonmarital fertility in the United States. Journal of Marriage and Family, 65 (1030-1040).

Sherif, M. S. (1936). The psychology of social norms. New York: Harper.

Sherif, C. W., Sherif, M. S., \& Nebergall, R. E. (1965). Attitude and attitude change. Philadelphia: W. B. Saunders Company.

Smith, S. W., Atkin, C. K., Martell, D., Allen, R., \& Hembroff, L. (2006). A social judgment theory approach to conducting formative research in a social norms campaign. Communication Theory, 16, 141-152.

Strauss, A., \& Corbin, J. (1990). Basics of qualitative research: Grounded theory procedures and techniques. Newbury Park, CA: Sage. 